\title{
Lutze, Maex, and Sieradzki to Chair 1996 MRS Fall Meeting Including ICEM-96 December 2-December 6
}

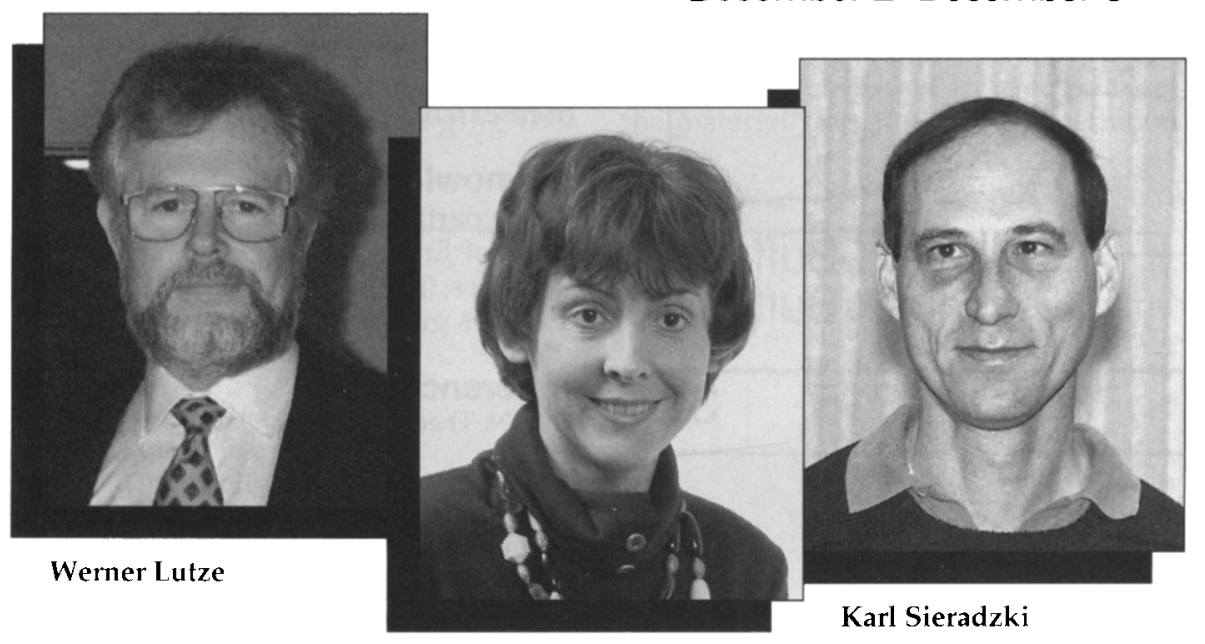

Karen Maex

Werner Lutze, Karen Maex, and Karl Sieradzki will serve as meeting chairs for the 1996 MRS Fall Meeting in Boston, which will be held in conjunction with ICEM-96 (International Conference on Electronic Materials), sponsored by the International Union of Materials Research Societies (IUMRS). The Materials Research Society meeting comprises 35 symposia, covering a range of cross-disciplinary topics including traditional topics and several new areas. Topics of growing interest include nitrides, high resolution imaging techniques, biomaterials, thin films and surfaces, and microstructural evolution in bulk phases.

New topics appearing at this meeting include electrochemical synthesis; integrated modeling from manufacturing through performance; materials for microsystems; low dielectric constant materials; environment, safety, and health issues in integrated-circuit (IC) production; solid-state chemistry of inorganic materials; and morphological control in multiphase polymer systems.

The meeting also offers a range of symposia on x-ray and neutron scattering, microstructural evolution during irradiation, catalytic materials, glass and glass formers-current issues, nanophase and nanocomposite materials, interfaces in structural and engineering materials, shape memory materials, intermetallic alloys, materials in art and archaeology, statistical mechanics in physics and biology, dynamics in small confining systems, high-temperature superconductivity, structure-property relationships in hardened cement pastes, and nuclear waste management.

ICEM-96 includes 12 of the 35 symposia in the areas of ion beam-solid interactions; defects in electronic materials; low dielectric constant materials; materials for microsystems; electronic packaging; amorphous and insulating crystalline thin films; environment, safety, and health issues in IC production; infrared applications of semiconductors; control of semiconductor surfaces and interfaces; group III nitrides; electrochemical synthesis; and nanocrystalline and microcrystalline semiconductors.

Werner Lutze is director of the Center for Radioactive Waste Management and a tenured professor at the University of New Mexico (UNM) in Albuquerque. For the past 25 years, he has worked in the field of radioactive waste. Lutze previously headed a materials research group at the Kernforschungszentrum Karlsruhe, lectured at the Universität Karlsruhe, and taught glass science at the University of
Aachen. Among his other research interests is a focus on glass science. Lutze received his $\mathrm{PhD}$ degree in chemistry from the Technische Universität Berlin. He organized the fifth and twelfth symposia in the MRS series on the Scientific Basis for Nuclear Waste Management, and was a principal editor of Journal of Materials Research.

Karen Maex heads a research team on Silicides and Interconnects within the Advanced Semiconductor Processing Division of the Interuniversity Microelectronics Center (IMEC), Leuven, Belgium. She is a senior research associate of the Belgian National Fund for Scientific Research. Maex is also a professor at the Katholieke Universiteit Leuven in Leuven, Belgium from where she received her MS degree in electrical engineering (1982) and her PhD degree (1987). Among her interests in materials science is technology for deep submicron semiconductor devices. Maex has been an organizer of the MRS symposium on Materials Synthesis and Processing Using Ion Beams (Fall 1993), on Advanced Metallization for Devices and Circuits-Science, Technology, and Manufacturability (Spring 1994), and on Silicide Thin Films: Fabrication Properties and Applications (Fall 1995).

Karl Sieradzki is an associate professor in the Department of Mechanical and Aerospace Engineering at Arizona State University. A graduate of Utica College of Syracuse University with a BS degree in physics, Sieradzki earned his MS and PhD degrees from Syracuse University in Materials and Solid State Science in 1978. His research interests are in the fracture of solids, corrosion and stress-corrosion cracking, and thin-film growth and morphology. He co-organized an MRS symposiuin on Mechanical Properties of Porous and Cellular Materials (Fall 1990), and serves as a Principal Editor for the Journal of Materials Research.

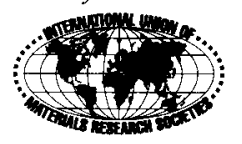

$\mathrm{M} \mid \mathrm{R} S$

\section{MRS Publications Catalog NOW AVAILABLE!}

Call (412) 367-3012 


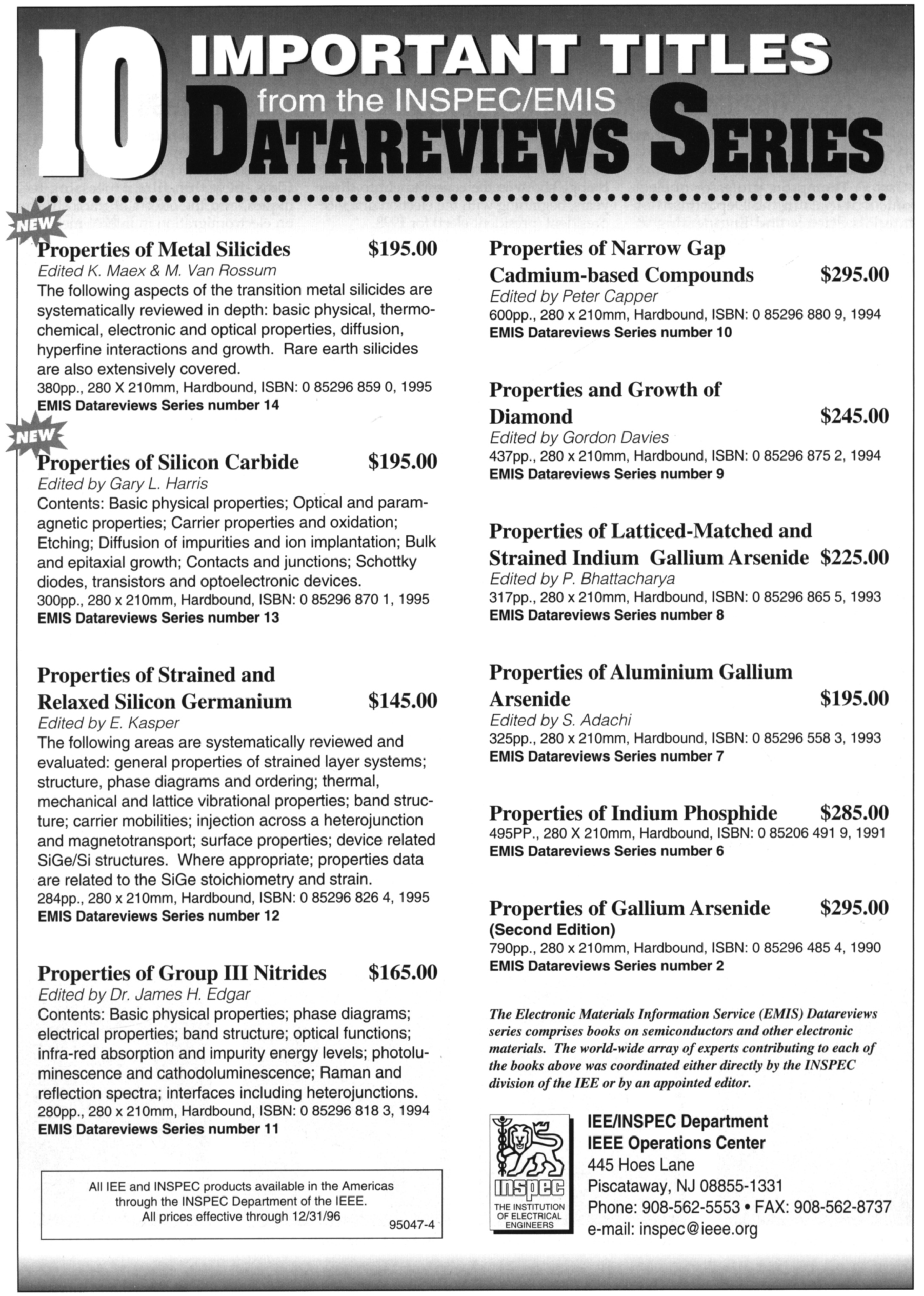

